\title{
CHANGES IN COLOUR AND MECHANICAL PROPERTIES OF WOOD POLYPROPYLENE COMPOSITES ON NATURAL WEATHERING
}

\author{
Jayashri Gunjal , Pankaj Aggarwal', Shakti Chauhan ${ }^{1, *}$
}

\begin{abstract}
This comparative study focused on understanding the effect of coupling agent and particle size on weathering behaviour of wood polypropylene composite. Two coupling agents, namely maleic anhydride grafted polypropylene and $m$-TMI ( $m$-Isopropenyl- $\alpha, \alpha-$ dimethylbenzyl isocyanate) grafted polypropylene were used in preparation of the composites. The composites were exposed to outdoor conditions for one year and changes in surface colour and mechanical properties were measured after 2, 4, 8 and 12 months of natural weathering. During the initial four months of weathering considerable colour change was observed with increase in lightness. Mechanical properties were unaffected largely for the initial four months and thereafter started declining. Overall, tensile strength decreased by about $15 \%$ and flexural strength decreased by about $8 \%$ after one year of weathering. The flexural modulus also decreased by about $10 \%$. Wood particle size was found to affect the aesthetic and strength of the composites after natural weathering. Coupling agents had a positive impact on mechanical properties however their influence on weathering degradation was not noticeable.
\end{abstract}

Keywords: Colour, flexural strength, mechanical properties, tensile strength, weathering, WPC.

\section{INTRODUCTION}

Application of lignocellulosic fibres as a reinforcement in thermoplastics has gained significant interest, and extensive research and development is taking place through-out the world. In this area, wood polymer composites (WPC), which are prepared by blending wood fibres or flour with recycled or virgin thermoplastic as raw materials, have become prominent due to availability of large quantities of wood and ease in processing of wood for such composites. Among thermoplastics, polypropylene (PP) is one of the most widely used polymers used for manufacturing of WPC. The wood component contributes by increasing stiffness and strength of the material while the thermoplastic component contributes towards moisture resistance, dimensional stability, decay resistance and thermoforming (Wolcott and Englund 1999). These composites are finding their suitability for variety of applications ranging from household items, construction industry, outdoor applications, automotive parts, etc. WPC properties are influenced by wood content, wood r particle size, coupling agent, polymer type, and additives.

Weathering resistance of WPC is very critical for the service life and performance of products meant for outdoor applications such as decking, garden furniture, facades, etc. Weathering involves degradation of material by sun-light, moisture and other pollutants presents in the air. In sun light, radiation wavelengths between $100 \mathrm{~nm}$ and $290 \mathrm{~nm}$ of the UV spectra are the most damaging to the surface of material (Klyosov 2007). Exposure to UV radiation for a prolonged period results mainly in surface discolouration and reduction in mechanical properties (Muasher and Sain 2006, Andrady et al. 1998). Degradation of WPC, initiated by UV radiation, accelerates by intermittent exposure to moisture and fluctuations in the temperature which can ultimately lead to a failure of the structure. It is postulated that the wood fibres in WPC are the major component 
attributing to the weathering of these composites. Photo-degradation affects the entire chemical constituents of wood with lignin being the most affected component. Lignin is converted into water soluble components on prolonged exposure to UV radiation. These compounds are washed away from wood surface when exposed to water, leaving a cellulose rich degraded surface (Poletto 2017). The thermoplastic component is also known to undergo photo-degradation (Homkhiew et al. 2014) although to a lesser extent than wood. Photo-degradation of thermoplastic is mainly attributed to the presence of some impurities like catalyst residues and UV sensitive functional groups in the polymers (Stark 2007).

Since both the components of WPC are prone to get affected by photo-degradation, a long -term exposure to outdoor condition may lead to changes in surface (colour and quality) and loss in mechanical properties (Fabiyi et al. 2008, Fabiyi and McDonald 2010). In addition, intermittent moisture absorption results in repeated swelling and shrinkage in wood fibres. The cyclic process ultimately leads to the development of fine cracks in WPC which facilitate UV penetration and further accelerates the degradation (Fabiyi and McDonald 2010). The use of an appropriate coupling agent is known to improve the interfacial adhesion between the two components and improves the wetting of fibres by the polymers which results in substantial increase in mechanical properties and reduced moisture absorption by the composite material. The effectiveness of the coupling agent in improving properties primarily depends on its functional group and grafting levels (Kale et al. 2016). Effective wetting of fibres and consequently encapsulation of fibres in the polymer may also influence the rate of photo-degradation of WPC.

Fibre dimensions also have a significant influence on the properties of WPC. Particle size of $180 \mathrm{~mm}$ to $300 \mathrm{~mm}$ with a fibre aspect ratio of 5,50 was found to give the superior mechanical properties (Chauhan et al. 2016). The fibre content in WPC is also known to have influence on weathering behaviour of WPC with higher fibre content resulting in more changes in lightness and colour (Adhikary 2008). The fibre dimension can also have an influence on weathering behaviour as the surface area of fibre exposed to weathering would be different for different fibre size classes.

The effect of coupling agent and fibre dimensions on weathering behaviour of WPC is still not completely understood. In this study, we report the natural weathering of wood-polypropylene composites having $40 \%$ wood fibres (by wt) and its effect on colour and mechanical properties.

\section{MATERIALS AND METHODS}

\section{Materials}

H110MA grade homopolymer PP (Reliance make) with a melt flow index (MFI) of $11 \mathrm{~g} \cdot 10 \mathrm{~min}^{-1}$ (at 230 ${ }^{\circ} \mathrm{C}$ under $2,16 \mathrm{~kg}$ load) was used in this study as the matrix material. Wood flour from Melia dubia was used as the reinforcement fibres. Laboratory synthesized $m$-isopropenyl- $\alpha, \alpha$-dimethylbenzyl isocyanate grafted polypropylene ( $m$-TMI-g-PP) and commercially available maleic anhydride grafted polypropylene (Fusabond MAPP, DuPont make; density - $903 \mathrm{~kg} / \mathrm{m}^{3}$; MFI- $120 \mathrm{~g} \cdot 10 \mathrm{~min}^{-1}$ ) were used as coupling agents. The $m$-TMIg-PP was prepared as per the procedure described by Chauhan et al. (2016) and was characterized with 5,6 $\%$ grafting percentage. Antioxidant, procured from Konkan Speciality Polyproducts Pvt. Ltd, Mangalore, and wax purchased from the local market were used as such during the preparation of composite materials.

\section{Methods}

\section{Wood pulverization and sieving}

Melia dubia wood billets were chipped and pulverized into flour/powder. The flour was fed into a gyrator screen to segregate the fibres into different particle size classes. Wood fibres passing through BSS standard mesh sizes $+60,-60+85$ and -100 were collected separately and kept in a hot air oven at $105^{\circ} \mathrm{C}$ for 24 hours to remove moisture. The oven dried wood fibres were used for the preparation of the composites. Wood fibres with +60 mesh sizes included all fibres which could not pass through 60 mesh. Similarly, wood fibres of -100 sizes were mix of very fine particles which were less than $0,1 \mathrm{~mm}$ in size. The fibre dimensions and the aspect ratio of different fractions are given in Table 1. 
Table 1: Measurements of Melia dubia wood particle.

\begin{tabular}{|c|c|c|}
\hline Mesh Size & Size & Average fibre aspect ratio \\
\hline+60 & $>0,250 \mathrm{~mm}$ & 4,35 \\
\hline$-60+85$ & $0,250-0,180 \mathrm{~mm}$ & 5,30 \\
\hline-100 & $<0,105 \mathrm{~mm}$ & 3,65 \\
\hline
\end{tabular}

\section{Preparation of composites}

Melia dubia wood flour (400 g), PP (580 g), coupling agent (20 g), antioxidant (10 g), and paraffin wax $(10 \mathrm{~g})$ were pre-mixed in a high-speed mixer. Composites were prepared with both MAPP and $m$-TMI-g-PP coupling agents. In addition, composites were also prepared without any coupling agent where $600 \mathrm{~g}$ of PP was used. The proportion of other additives was the same as in composites with coupling agent. The composites were prepared using a co-rotating twin screw extruder having $25 \mathrm{~mm}$ screw diameter and L/D ratio of 42 . The extruder was having six segmented barrels and the temperature of the barrels were set from $168^{\circ} \mathrm{C}$ (at the feeder zone) to $180^{\circ} \mathrm{C}$ (at the die head) during compounding. The pre-mixed blend of wood, polymer and additives was fed at a consistent rate into the extruder with the help of a feeder and the main screw RPM of the extruder was set to 100. Output of the extruder was in the form of $3 \mathrm{~mm}$ diameter continuous strands. The strands were fed into a palletizer to obtain granules. The granules were oven dried at $85{ }^{\circ} \mathrm{C}$ for 24 hours. Compounding was done with the different particle size (BSS standard Mesh $+60,-60+85$ and -100 ) of wood flour.

Composite granules were injection moulded into test specimens as per ASTM D790-15 (2015) for flexural properties $(127 \mathrm{~mm} \times 12,6 \mathrm{~mm} \times 6,6 \mathrm{~mm}$; rectangular bar) and ASTM D638-14 (2014) for tensile properties (165 mm $\times 13 \mathrm{~mm} \times 3,35 \mathrm{~mm}$; dumbbell shape) using a 60-tonne L\&T Demag microprocessor controlled, closed loop injection moulding machine. The moulded specimens were kept in desiccators over silica for 24 hours before mechanical testing.

\section{Natural weathering}

The injection moulded samples (tensile and flexural test samples) were exposed to outdoor conditions on the roof-top of the laboratory building. The specimens were fixed on a custom-made aluminium rack (Figure 1). The rack was oriented in North-South direction to get maximum sunlight on the samples. Only one side of the sample was exposed to weathering. A set of five specimens were removed from the exposure rack after 2, 4,8 , and 12 months of outdoor weathering and analyzed for colour changes and mechanical properties. This exposure and removal schedule allowed for property evaluation across seasons.

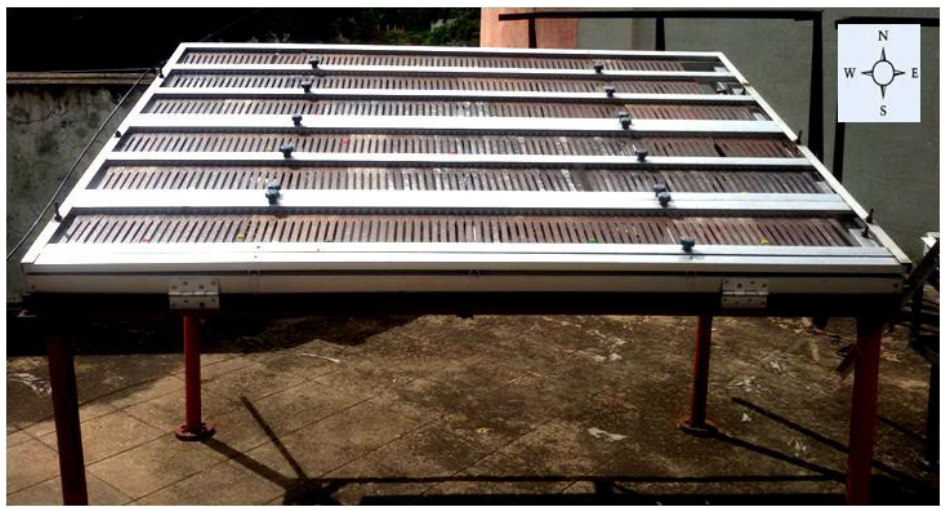

Figure 1: Exposed WPC samples to natural conditions. 


\section{Colour measurement}

Three-dimensional colour parameters measuring lightness of the sample $\left(\mathrm{L}^{*}\right)$ and colour coordinates $\left(\mathrm{a}^{*}\right.$ for redness and $b^{*}$ for yellowness) of WPC specimens were recorded before and after weathering using a LabScan XE spectrophotometer. The surface colour parameters were measured at three different positions for each specimen. The colour difference $\left(\Delta \mathrm{E}^{*}\right)$ was calculated using Equation 1:

$$
\Delta E^{*}=\sqrt{\left(\Delta L^{*}\right)^{2}+\left(\Delta a^{*}\right)^{2}+\left(\Delta b^{*}\right)^{2}}
$$

Where, $\Delta \mathrm{L}^{*}, \Delta \mathrm{a}^{*}$, and $\Delta \mathrm{b}^{*}$ represent the differences between the initial and final values of $\mathrm{L}^{*}, \mathrm{a}^{*}$, and $\mathrm{b}^{*}$, respectively.

\section{Mechanical testing}

Mechanical properties (tensile and flexural strength and flexural modulus) were performed using a $10 \mathrm{KN}$ universal testing machine (Shimatzu make, model AGIS10). Tensile tests were conducted in accordance with ASTM D638-94b (2014). The crosshead speed was $50 \mathrm{~mm} / \mathrm{min}$. Flexural strength test was done as per ASTM D790-92 (2015) with a support span of $100 \mathrm{~mm}$ and the crosshead speed of 2,8 $\mathrm{mm} / \mathrm{min}$. For each test, five replicates at each stage were tested. Data was analyzed using SPSS ver.16 statistical software.

\section{Scanning electron microscope}

The surface of weathered composite sample was observed using TESCAN VEGA3 scanning electron microscope (SEM) operating at $10 \mathrm{kV}$. Prior to observation, samples were coated with gold layer using a sputter coater.

\section{RESULTS AND DISCUSSION}

\section{Effect of natural weathering on the surface colour of WPCs}

To study the effect of natural weathering on WPC samples; composite compounded with different wood particle sizes and coupling agents at $40 \%$ wood loading. The changes in the colour of the WPC samples from outdoor exposure were recorded in terms of lightness, yellowness and redness. The surface colour was measured after 2, 4, 8 and 12 months of outdoor exposure. The change in lightness of the composites prepared with different wood particle sizes and coupling agents due to weathering is given in Table 2 . 
Table 2: The lightness $\left(\mathrm{L}^{*}\right)$ values of the composites with natural weathering. The values in parenthesis are standard deviation of 15 measurements ( 3 measurements per sample).

\begin{tabular}{|c|c|c|c|c|c|c|c|}
\hline \multirow{2}{*}{ S. No } & \multirow{2}{*}{$\begin{array}{c}\text { Particle } \\
\text { Size }\end{array}$} & \multirow{2}{*}{$\begin{array}{c}\text { Coupling } \\
\text { agent }\end{array}$} & \multicolumn{5}{|c|}{ Months } \\
\cline { 4 - 8 } & & & \multicolumn{5}{|c|}{ Lightness } \\
\cline { 4 - 8 } & & & $\mathbf{6}$ & $\mathbf{4}$ & $\mathbf{8}$ & $\mathbf{1 2}$ \\
\hline 1 & +60 & MAPP & $28(1,8)$ & $53(2,6)$ & $63(3,3)$ & $66(1,4)$ & $60(2,3)$ \\
\hline 2 & $-60+85$ & MAPP & $31(1,6)$ & $51(2,3)$ & $65(2,0)$ & $65(1,4)$ & $64(1,0)$ \\
\hline 3 & -100 & MAPP & $27(4,5)$ & $62(3,1)$ & $71(1,7)$ & $70(0,6)$ & $70(1,0)$ \\
\hline 4 & +60 & m-TMI & $30(0,3)$ & $49(4,6)$ & $63(3,7)$ & $63(2,3)$ & $61(1,3)$ \\
\hline 5 & $-60+85$ & m-TMI & $30(1,4)$ & $52(3,6)$ & $65(4,0)$ & $66(2,0)$ & $63(1,7)$ \\
\hline 6 & -100 & m-TMI & $27(2,4)$ & $60(3,4)$ & $69(1,3)$ & $69(1,2)$ & $69(2,4)$ \\
\hline 7 & +60 & Control & $27(1,5)$ & $53(3,3)$ & $65(2,0)$ & $65(2,9)$ & $62(1,5)$ \\
\hline 8 & $-60+85$ & Control & $29(2,0)$ & $54(2,8)$ & $66(1,7)$ & $67(1,3)$ & $65(0,8)$ \\
\hline 9 & -100 & Control & $29(3,1)$ & $64(1,6)$ & $74(1,0)$ & $71(1,9)$ & $71(1,1)$ \\
\hline
\end{tabular}

The lightness ( $\mathrm{L}^{*}$ value) of the composites prior to weathering was in the range of 27-31 for all the composites irrespective of particle size or coupling agent. With the outdoor exposure, the $\mathrm{L}^{*}$ values of the composite increased for the first four months and thereafter it stabilized or reduced slightly. The trend was similar in all types of composite formulations. Generally, wood and virgin polypropylene becomes dark on weathering which is in contrast to the increased lightness of WPC. This might be because that during compounding of wood with polymer at high temperature $\left(\sim 180^{\circ} \mathrm{C}\right)$, the wood component undergoes thermal degradation/ modification resulting in a dark coloured composite material. Thermally modified wood has been reported to become lighter in colour on exposure to UV radiation (Srinivas and Pandey 2012). During weathering process in the initial period photo-bleaching of the surface due to UV radiation would be the attributing factor for increased lightness. The lignin component of wood is mostly affected by the photo-bleaching (Stark and Matuana 2006).

Among the particle sizes, composites prepared with smaller wood particles (Mesh size -100) exhibited relatively more increase in $\mathrm{L}^{*}$ values in the first four months as compared to other two particle sizes through-out the study period. This may be attributed to the large surface area of wood in the composites with small particle sizes. With high surface area of wood, the complete encapsulation with polypropylene matrix would be less likely. Increased lightness in WPC with increasing wood content has been reported by Adhikary (2008). There was no influence of coupling agents on the lightness change of composite samples after one year of outdoor weathering as both coupled and uncoupled composites exhibited similar $\mathrm{L}^{*}$ values for a specific particle size class. Colour measurement also revealed loss in redness $\left(\mathrm{a}^{*}\right)$ and yellowness $\left(\mathrm{b}^{*}\right)$ during the outdoor exposure. The decrease in yellowness $\left(\Delta \mathrm{b}^{*}\right)$ with exposure time has been attributed to the photo-bleaching of the surface (Muasher and Sain 2006).

The total colour change $\left(\Delta \mathrm{E}^{*}\right)$ of the composite is shown in Figure 2. The trend of total colour change was like that observed for lightness. Rapid colour change $\left(\Delta \mathrm{E}^{*}\right)$ was observed in the initial four months of the exposure period and thereafter the values were stabilized in almost all the cases. The wood particle size and coupling agents exhibited slight influence in the total colour change of the composites after outdoor weathering of 12 months. Composites prepared with -100 mesh size particles exhibited higher colour change through-out the one year of natural weathering. There was no remarkable difference in colour changes in composites with +60 and $-60+85$ particle size except in case of m-TMI-g-PP coupling agent (Figure 2b) where the total colour change in composites with +60 mesh size exhibited the lowest colour change and the difference between +60 and $-60+85$ particles was statistically significant. The composites with large particles $(+60$ mesh) and with m-TMI-g-PP coupling agent exhibited the least colour change $\left(\Delta E^{*}=28\right)$ among all the composites after 12 months of weathering. For all other formulations, total colour change was nearly the same at different periods. It is therefore can be inferred that coupling agent has no significant influence on total colour change of the composites during weathering. The surface colour change is mainly due to chemical and physical changes in both wood and polymer on UV exposure (Matuana et al. 2011). Higher magnitude of colour changes in composites with finer particles (-100) might be attributed to the large surface area of wood with finer particles exposed to weathering. 


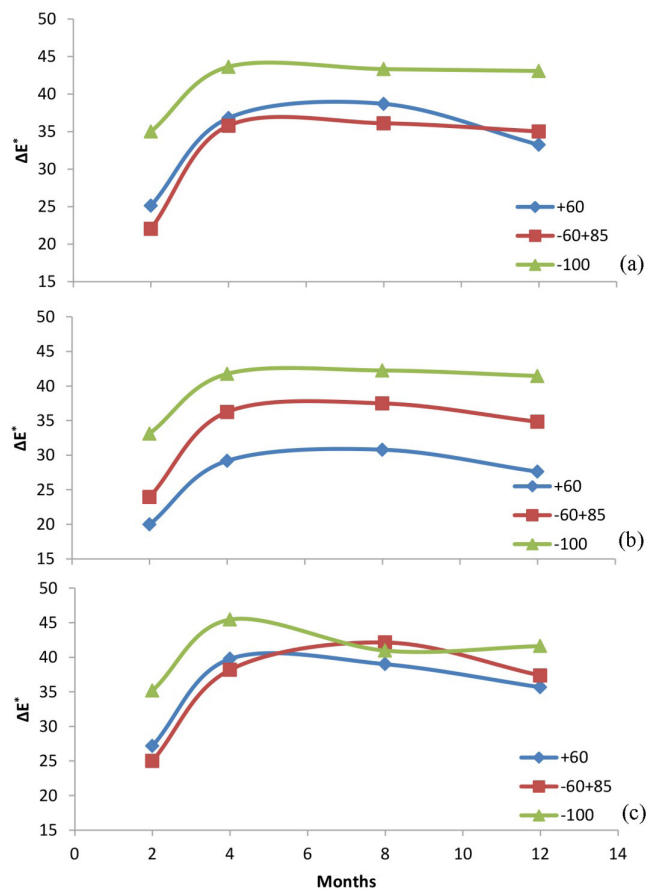

Figure 2: Total colour change $\left(\Delta \mathrm{E}^{*}\right)$ of the weathered composite after outdoor exposure (a) With MAPP coupling agent (b) with m-TMI-g-PP coupling agent (c) without any coupling agent.

\section{Effect of natural weathering on mechanical properties of WPCs}

The effect of weathering on tensile strength, flexural strength and flexural modulus of composites is an important parameter determining the performance of the product to the outdoor use. These mechanical properties of the composite materials were evaluated prior to weathering and after 2, 4, 8, and 12 months of weathering. Tensile and flexural strengths of all the composites subjected to weathering are given in Table 3 and Table 4 respectively.

Table 3: Tensile strength of the composite material before and after weathering. The value in parenthesis is standard deviation.

\begin{tabular}{|c|c|c|c|c|c|c|c|}
\hline \multirow{2}{*}{ S. No } & \multirow{2}{*}{$\begin{array}{c}\text { Particle } \\
\text { Size }\end{array}$} & \multirow{2}{*}{$\begin{array}{c}\text { Coupling } \\
\text { agent }\end{array}$} & & \multicolumn{5}{|c|}{ Months } \\
\cline { 5 - 8 } & & & $\mathbf{5}$ & $\mathbf{5}$ & $\mathbf{4}$ & $\mathbf{8}$ & $\mathbf{1 2}$ \\
\hline & & & \multicolumn{5}{|c|}{ Tensile strength (MPa) } \\
\hline 1 & +60 & MAPP & $36,5(1,1)$ & $35,1(0,7)$ & $30,9(0,5)$ & $30,8(0,3)$ & $30,7(0,8)$ \\
\hline 2 & $-60+85$ & MAPP & $38,7(0,6)$ & $38,3(0,5)$ & $37,8(0,8)$ & $35,9(1,2)$ & $35,6(1,4)$ \\
\hline 3 & -100 & MAPP & $35,8(1,1)$ & $35,9(1,2)$ & $33,3(0,7)$ & $33,1(0,8)$ & $32,1(1,1)$ \\
\hline 4 & +60 & m-TMI & $38,1(0,9)$ & $36,6(1,3)$ & $33,9(0,6)$ & $29,8(0,8)$ & $30,0(1,3)$ \\
\hline 5 & $-60+85$ & m-TMI & $39,4(0,8)$ & $39,8(1,5)$ & $36,8(0,5)$ & $34,6(0,3)$ & $33,4(0,7)$ \\
\hline 6 & -100 & m-TMI & $38,4(1,7)$ & $36,8(1,1)$ & $35,4(1,9)$ & $34,8(0,8)$ & $34,6(1,1)$ \\
\hline 7 & +60 & Control & $31,6(0,9)$ & $30,7(0,8)$ & $30,8(0,6)$ & $28,1(0,6)$ & $28,3(0,2)$ \\
\hline 8 & $-60+85$ & Control & $30,5(0,6)$ & $30,1(0,9)$ & $29,5(0,7)$ & $28,1(0,6)$ & $26,4(0,4)$ \\
\hline 9 & -100 & Control & $28,3(0,6)$ & $28,4(0,9)$ & $27,1(0,3)$ & $26,3(0,7)$ & $26,4(0,8)$ \\
\hline
\end{tabular}


Table 4: Flexural strength of the composite material before and after weathering. The value in parenthesis is standard deviation.

\begin{tabular}{|c|c|c|l|l|l|l|l|}
\hline \multirow{2}{*}{ S. No } & \multirow{2}{*}{$\begin{array}{c}\text { Particle } \\
\text { Size }\end{array}$} & \multirow{2}{*}{$\begin{array}{c}\text { Coupling } \\
\text { agent }\end{array}$} & \multicolumn{5}{|c|}{ Months } \\
\cline { 4 - 8 } & & & $\mathbf{0}$ & \multicolumn{5}{|c|}{$\mathbf{2}$} & $\mathbf{4}$ & $\mathbf{8}$ & $\mathbf{1 2}$ \\
\cline { 4 - 8 } & & & \multicolumn{5}{|c|}{ Flexural strength (MPa) } \\
\hline 1 & +60 & MAPP & $55,6(1,1)$ & $54,7(2,3)$ & $54,3(0,6)$ & $54,4(0,7)$ & $51,8(0,5)$ \\
\hline 2 & $-60+85$ & MAPP & $58,8(1,8)$ & $60,5(1,3)$ & $59,6(2,1)$ & $56,3(0,9)$ & $54,6(1,6)$ \\
\hline 3 & -100 & MAPP & $54,6(0,3)$ & $55,1(0,7)$ & $55,3(0,6)$ & $54,7(0,8)$ & $51,8(0,6)$ \\
\hline 4 & +60 & m-TMI & $59,8(0,5)$ & $60,5(0,5)$ & $60,2(0,7)$ & $55,5(0,2)$ & $54,6(0,9)$ \\
\hline 5 & $-60+85$ & m-TMI & $62,9(2,0)$ & $63,4(1,1)$ & $61,7(0,8)$ & $59,7(2,0)$ & $58,8(1,1)$ \\
\hline 6 & -100 & m-TMI & $59,7(0,8)$ & $60,3(3,1)$ & $60,2(2,2)$ & $58,4(0,8)$ & $57,7(2,2)$ \\
\hline 7 & +60 & Control & $46,4(0,6)$ & $44,9(1,3)$ & $44,4(1,2)$ & $43,3(0,6)$ & $42,5(0,9)$ \\
\hline 8 & $-60+85$ & Control & $46,9(0,4)$ & $45,9(0,6)$ & $44,8(0,7)$ & $43,8(1,5)$ & $43,7(0,4)$ \\
\hline 9 & -100 & Control & $45,1(0,7)$ & $44,6(0,8)$ & $43,6(0,4)$ & $41,5(0,9)$ & $42,5(0,6)$ \\
\hline
\end{tabular}

The results clearly indicate that for a specific particle size, the strength properties of the composites with coupling agents were significantly higher than of composites without any coupling agent. Analysis of variance also indicated significant effect of coupling agent on the strength. This is attributed to superior interfacial adhesion between fibre and matrix polymer in the presence of a coupling agent. Between the two coupling agents, properties of the composites with m-TMI-g-PP coupling agent were better than MAPP. The superiority of m-TMI-g-PP over MAPP has already been proved by Chauhan et al. (2016). The effect of particle size on the properties was also very evident where composites prepared with $-60+85$ mesh size fibre exhibited the best properties for both the coupling agents. The results are in congruence with the results reported by Chauhan et al. (2016). The strength of the composites with coupling agent was relatively unchanged for the initial 2 to 4 months of weathering and thereafter exhibited slight decline. A paired t-test also indicated no significant difference in strength properties of composites in the first four months with respect to strength before weathering. However, the strength values were significantly lower than initial strength after 12 months of weathering. The composites prepared using large particles (i.e. +60 mesh sizes) exhibited relatively more loss in strength compared to other two size classes. Tensile strength reduction after 12 months of weathering was $15,8 \%, 21,3$ $\%$ and $10,4 \%$ for MAPP, m-TMI-g-PP and uncoupled composites, respectively for +60 mesh wood fibre. The loss in mechanical strength may be attributed to the reduced interfacial adhesion with weathering and loosening of the fibres. Retention of mechanical properties with small particle composite can be explained by the fact that small wood particles composites are more homogenous than the composites with large wood fibres.

Flexural strength also declined with weathering though the magnitude was lower than for tensile strength. The presence of coupling agent did not prevent loss in mechanical properties. The composites containing both compatibilizers showed almost same loss in flexural strength after one year. Interestingly, in most of the coupled composites, the flexural strength increased slightly in the first two months of weathering and then declined. This may be attributed to the increased crystallinity of the mobile short chains of PP with the initial exposure to UV light and water, and changes in the molecular weight occurring due to polymer degradation followed by chain scission and recrystallization (Fabiyi and McDonald 2014). The continuous weathering leads to excessive chain scission of PP, degradation and erosion of wood ultimately adversely affecting mechanical strength (Stark and Matuana 2006).

The initial flexural modulus (prior to weathering) was ranging from $3172 \mathrm{MPa}$ to $3844 \mathrm{MPa}$ for different formulations. There was no specific difference in the modulus values with coupling agents. The average modulus for three fibre size classes is shown in Figure 3. The maximum modulus values were observed in the fibre size class $-60+85$. 


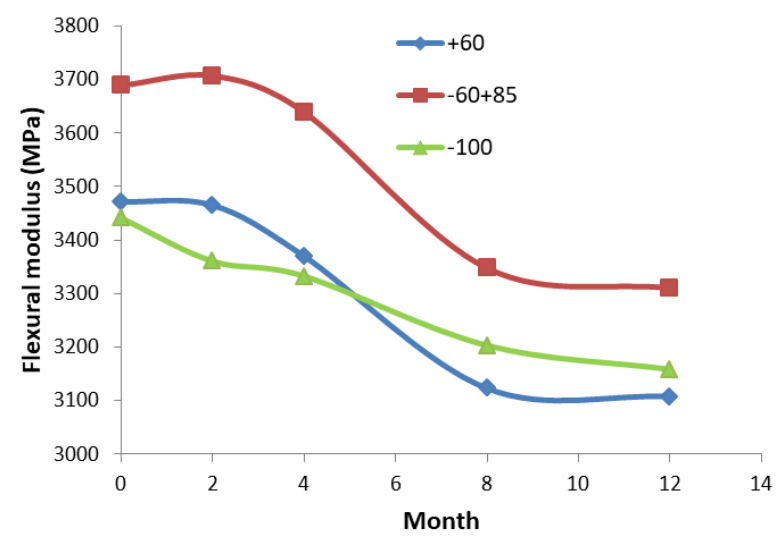

Figure 3: Changes in flexural modulus of composites with natural weathering.

The modulus values remained unaltered for initial four months of weathering and thereafter declined in a similar fashion in both +60 and $-60+85$ composites. Overall, the flexural modulus reduced by about $10 \%$ with respect to the initial values after one year of weathering. Eshraghi et al. (2016) also observed about $10 \%$ decline in flexural modulus of HDPE-wood composites after $2000 \mathrm{~h}$ of artificial weathering. It was observed that the loss in flexural modulus in the composites containing smaller wood particle size (Mesh size -100) was relatively lesser as compared to other two wood particle sizes. The reduction in elastic modulus may be attributed to the loosening of surface fibres due to weathering and their wash-off with exposure to water during rains and also due to increase moisture content of fibres in the composites.

The changes in colour and loss in mechanical properties of the composites due to natural weathering and its dependency on particle size suggests the need to optimize the formulations for outdoor applications. It was observed that, initially, weathering affects the colour of the composites without having any significant influence on the mechanical properties as during the initial period of weathering only surface of the composites is affected. However, with continuous weathering, the surface tends to develop micro cracks (Homkhiew et al. 2014) and the fibres in the inner core get exposed for UV radiation and water resulting in their swelling and degradation. Scanning electron microscopic analysis of weathered sample clearly indicates development of number of micro-cracks on the surface of the sample (marked by the arrow-marks) and also surface erosion after one year of weathering (Figure 4).

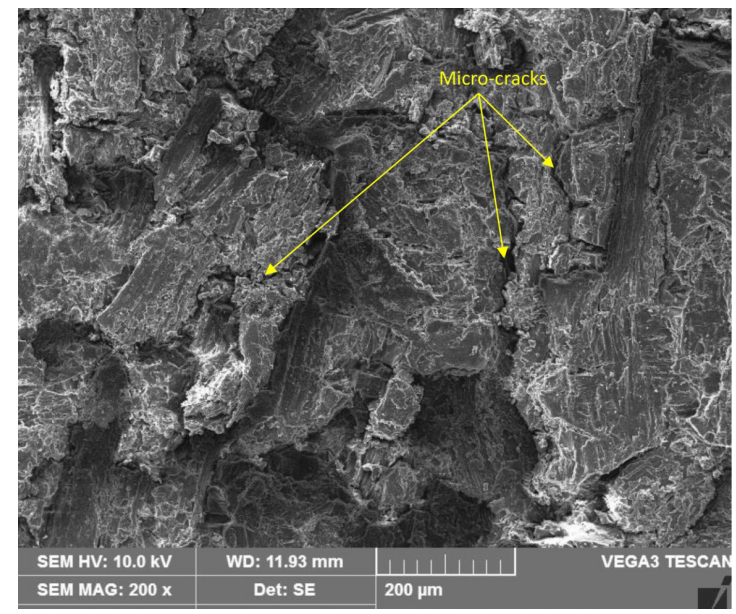

Figure 4: Scanning electron microscopic image of weathered sample. 
The developed micro-cracks may reduce the efficiency of stress transfer from matrix to fibre (Cherian et al. 2013, Zhang et al. 2010) resulting in strength loss. Though the loss in mechanical properties was about 10 $\%$ after one year of weathering, it may further accelerate the degradation process and further reduction in the properties. Therefore, studies with further long-term exposure in outdoor condition are required to assess the performance of these composites.

\section{CONCLUSIONS}

The influence of natural weathering on the mechanical and aesthetic properties of WPCs was investigated. The effect of coupling agent and wood particle size on the mechanical and physical behaviour of weathered and un-weathered samples was also studied. Natural weathering increased the lightness and total colour change of composite samples after one year of exposure. The maximum colour change was observed in the initial four months of exposure in outdoor condition. The colour change of WPC was found to depend on wood particle size. Composites with larger wood particle size were characterized with better colour stability than small particle size. The presence of coupling agent in the composite formulation has no influence on surface colour change during weathering. The effect of weathering on mechanical properties was observed only after four months of exposure. Composites with fine wood particle size exhibited better mechanical properties.

\section{ACKNOWLEDGEMENTS}

The authors would like to acknowledge the Director and Group Coordinator Research, Institute of Wood Science and Technology, Bangalore for their encouragement and support to carry out this study. The authors are thankful to the Indian Council of Forestry Research and Education for the financial support to the project "Biological Degradation and Weathering Behavior of Wood Polymer Composites (IWST/WSP/XI/141). The help extended by Mr. V. Krishna, Technical Officer in carrying out the experiments is duly acknowledged.

\section{REFERENCES}

ASTM International. ASTM. 2014. Standard Test Method for Tensile Properties of Plastics. ASTM. D638-14. 2014. ASTM International: West Conshohocken, PA, USA. https://doi.org/10.1520/D0638-14

ASTM International. ASTM. 2015. Standard test methods for flexural properties of unreinforced and reinforced plastics and electrical insulating materials. ASTM. D790-15. 2015. ASTM International: West Conshohocken, PA, USA. https://doi.org/10.1520/D0790-15

Adhikary, K.B. 2008. Development of wood flour-recycled polymer composite panels as building materials. (Ph.D. thesis). University of Canterbury, Christchurch, New Zealand, 229p. http:/hdl.handle. net/10092/1795

Andrady, A.L.; Hamid, S.H.; Hu, X.; Torikai, A. 1998. Effects of increased solar ultraviolet radiation on materials. J Photochem Photobiol B 46(1-3): 96-103. https://doi.org/10.1016/S1011-1344(98)00188-2

Chauhan, S.; Aggarwal, P.; Karmarkar A. 2016. The effectiveness of m-TMI-grafted-PP as a coupling agent for wood polymer composites. J Compos Mater 50(25): 3515-3524. https://doi. org/10.1177/0021998315622050 
Cherian, B.M.; Leao, A.L.; Chaves M.R.D.M.; Souza S.F. D.; Sain, M.; Narine, S.S. 2013. Environmental ageing studies of chemically modified micro and nanofibril phenol formaldehyde composites. Ind Crops Prod 49: 471-483. https://doi.org/10.1016/j.indcrop.2013.04.033

Eshraghi, A.; Khademieslam, H; Ghasemi, I. 2016. Effect of weathering on physical and mechanical properties of hybrid nanocomposite based on polyethylene, wood flour and nanoclay. Maderas. Ciencia y tecnología 18(4): 617-626. http://dx.doi.org/10.4067/S0718-221X2016005000054

Fabiyi, J.S.; McDonald, A.G. 2014. Degradation of polypropylene in naturally and artificially weathered plastic matrix composites. Maderas-Cienc Tecnol 16(3): 275-290. http://dx.doi.org/10.4067/S0718221X2014005000021

Fabiyi, J.S.; McDonald, A.G. 2010. Effect of wood species on property and weathering performance of wood plastic composites. Compos Part A Appl Sci 41(10): 1434-1440. https://doi.org/10.1016/j.compositesa.2010.06.004

Fabiyi, J.S.; McDonald, A.G.; Wolcott, M.P.; Griffiths, P.R. 2008. Wood plastic composites weathering: Visual appearance and chemical changes. Polym Degrad Stab 93(8): 1405-1414. https://doi.org/10.1016/j. polymdegradstab.2008.05.024

Homkhiew, C.; Ratanawilai, T.; Thongruang, W. 2014. Effects of natural weathering on the properties of recycled polypropylene composites reinforced with rubberwood flour. Ind Crops Prod 56: 52-59. https:// doi.org/10.1016/j.indcrop.2014.02.034

Kale, A.; Raghu, N.; Natu, H.P.; Aggarwal, P.; Chauhan, S. 2016. Effect of grafting yield and molecular weight of $m$-TMI-grafted-PP on the mechanical properties of wood fibre filled polypropylene composites. J App Polym Sci 133(46). https://doi.org/10.1002/app.44196

Klyosov, A.; 2007. Wood-Plastic Composites. Wiley \& Sons, Inc. New Jersey, USA. 698p. https://doi. org/10.1002/9780470165935

Matuana, L.M.; Jin, S.; Stark, N.M. 2011. Ultraviolet weathering of HDPE/wood-flour composites coextruded with a clear HDPE cap layer. Polym Degrad Stab 96(1): 97-106. https://doi.org/10.1016/j.polymdegradstab.2010.10.003

Muasher, M.; Sain, M. 2006. The efficacy of photostabilizers on the colour change of wood filled plastic composites. Polym Degrad Stab 91(5): 1156-1165. https://doi.org/10.1016/j.polymdegradstab.2005.06.024

Poletto, M. 2017. Comparative study of wood flour photodegradation of two wood species submitted to artificial weathering. Maderas-Cienc Tecnol 19(2): 141-148. http://dx.doi.org/10.4067/S0718$221 \times 2017005000012$

Srinivas, K.; Pandey, K.K. 2012. Photodegradation of thermally modified wood. J Photochem Photobiol $B$ 117: 140-145. https://doi.org/10.1016/j.jphotobiol.2012.09.013

Stark, N.M. 2007. Considerations in the weathering of wood-plastic composites. In Proceedings, $3^{\text {rd }}$ wood fibre polymer composites international symposium. Bordeaux, France. March 26-27, 2007. 10 p. https://www. fs.usda.gov/treesearch/pubs/27307

Stark, N.M.; Matuana, L.M. 2006. Influence of photostabilizers on wood flour-HDPE composites exposed to xenon-arc radiation with and without water spray. Polym Degrad Stab 91 (12): 3048-3056. https:// doi.org/10.1016/j.polymdegradstab.2006.08.003

Wolcott, M.P.; Englund, K. 1999. A technology review of wood-plastic composites. In Proceedings of the 33rd International Particleboard and Composite Materials Symposium. Pullman, WA, USA. 8p.

Zhang, M.; Du, H.; Wang, W.H.; Wang, Q.W. 2010. Property changes of wood-fibre/HDPE composites colored by iron oxide pigments after accelerated UV weathering. $J$ For Res 21(1): 59-62. https://doi. org/10.1007/s11676-010-0009-Z 